\title{
策 \\ TRANSPARÊNCIA QUANTO À ARQUITETURA DA INFORMAÇÃO E USABILIDADE: CASO DO PORTAL DA ASSEMBLEIA LEGISLATIVA DO ESTADO DO PARANÁ
}

\author{
TRANSPARENCY AS TO INFORMATION ARCHITECTURE AND USABILITY: \\ CASE OF THE PARANÁ STATE LEGISLATIVE ASSEMBLY
}

\author{
TRANSPARENCIA EN CUANTO A ARQUITECTURA DE INFORMACIÓN Y \\ USABILIDAD: CASO DE LA ASAMBLEA LEGISLATIVA DEL ESTADO DE \\ PARANÁ
}

Jackeline Saori Teixeira $^{1}$

\begin{abstract}
Resumo: Parte considerável da literatura sobre transparência pública se debruça somente sobre as exigências legais. À vista disso, propõe-se a observar o caso da Assembleia Legislativa do Estado do Paraná, especificamente o sítio online institucional, mediante a perspectiva da a rquitetura da informação e usabilidade, de modo a investigar como é pratica da a transparência pela instituição atra vés do sítio virtual. Para isso, utiliza-se a técnica de observação sistemática e uma lista de verificação. Observaram-se problema s quanto à nomeação a mbígua da s categoria s nos menus, ordenação das informações nas pá ginas secundária s e a a presentação das informações de forma não facilita da ao usuário. Desse modo, compreendese que o foco da transparência online realizada pela instituição não se restringe ao constrangimento legal, mas se refere a uma concepção dos próprios a gentes sobre o que ela seria.
\end{abstract}

Palavras-chave: Transparência; Arquitetura da Informação; Usabilidade; Democracia Digital; Comunicação Política.

Abstract: The major part of public transparency literature only talks about legal requirements. It proposes to look at the case of Paraná State Legislative Assembly, specifically the institutional website, through the information architecture's and usability's perspective to investigate how the institution practiced website transparency. So, it uses systematic observation and checklist. Problems about the ambiguous nomination of menu categories, information order in secondary pages, and non-facilitated a vailability information have observed. This way, it is comprehended that the focus of online transparency is not restricted by legal requirements however it refers to agents' conception.

Key-words: Transparency; Information Architecture; Usability; Digital Democracy; Political Communication.

Resumen: Parte considerable de la literatura sobre transparencia publica habla solamente sobre las exigencias legales. En vista de eso, se propone a observarel caso de la Asamblea Legislativa del Estado de Paraná, específicamente el sitio online institucional, mediante la perspectiva de la arquitectura de informa ción e usabilidad, de modo a investigar cómo la transparencia es practica da por la institución atreves de lo sitio virtual. Para eso, utiliza-se la técnica de observación sistemática e lista de verificación. Observaran-se problemas cuanto a nominación a mbigua de las categorías en los menús, ordenación de las informaciones en las páginas secundarias e la presentación de informaciones de forma non facilitada para los usuarios. De ese modo, comprende-se que el foco de la transparencia online rea lizada por la institución no se restringe al embarazo legal, pero se refiere a una concepción de los propios agentes sobre lo que ella sería.

\footnotetext{
${ }^{1}$ Mestranda em Ciência Política pela Universidade Federal do Paraná. Orcid Id: https://orcid.org/0000-0002-8828 2158. E-mail: jackeline_st@ hotmail.com.
} 
Palabras clave: Transparencia; Arquitectura de la Información; Usabilidad; Democracia Digital; Comunicación Política.

\section{Introdução}

A atuação brasileira quanto a transparência não se restringe às práticas internas, mas também abarca relações internacionais; como no trabalho junto à Open Government Partnership (OGP), iniciativa internacional a qual o Brasil é membro-fundador, que em 2016, apresenta o $3^{\circ}$ Plano de Ação Nacional para Governo Aberto. O compromisso número 11 desse documento tem como objetivo principal aprimorar a abertura transparente participativa de casas legislativas, por meio da soma de esforços de diferentes atores na busca de soluções inovadoras e abertas (BRASIL, 2016). Tal preocupação pode ser compreendida devido às mudanças decorrentes das matérias legais mencionadas anteriormente que não abordavam os atributos para o aumento da transparência nos órgãos do Legislativo e do Judiciário.

O caso da Assembleia Legislativa do Estado do Paraná (ALEP) se mostra relevante não somente pelo compromisso; mas também pelo interesse de $82 \%$ dos paranaenses em conhecer melhor a instituição e pela comunicação institucional da Casa não se utilizar da veiculação patrocinada de informações para divulgar suas atividades na mídia, o que ocorre em sete dentre as dez Assembleias dos Estados brasileiros com o maior Produto Interno Bruto (AERP, 2019). A ALEP lançou em 2019 o primeiro edital referente à prestação de serviços de publicidade institucional (RIBEIRO, 2019), cujo o objetivo é difundir ideias, informar o público em geral e tornar mais transparente a comunicação da Casa (ALONSO, 2019). Tal conduta demonstra mudança de postura quanto publicização e transparência institucional.

Nesse sentido, busca-se responder a seguinte questão de pesquisa: como é praticada a transparência institucional da ALEP? Entende-se que a resposta à indagação pode perpassar diversas áreas do conhecimento, para isso se valeu de um estudo descritivo do portal a partir da perspectiva da arquitetura da informação e usabilidade. Tais conceitos foram elencados dada a perspectiva de que a instauração de mecanismos de transparência pode ser somente um meio de cumprir o ordenamento legal, sem cuidados adicionais com os possíveis utilizadores, ou pode ser um sinal de que existe algum grau de preocupação com o cidadão que terá acesso a tais ferramentas o que proporcionaria a busca por elaborar dispositivos que cumpram mais que somente as exigências legais. No caso da presente pesquisa entende-se que a preocupação com o usuário se mostra ao proporcionar interfaces que sigam os critérios comuns de usabilidade na Internet.

Dá-se atenção especial para a disposição e apresentação das informações no portal da Assembleia, visto que o público das atividades atreladas à transparência contempla desde os órgãos de fiscalização de tais políticas até a população como um todo. As seções seguintes do trabalho são organizadas de modo a (I) oferecer uma revisão da literatura relacionada na qual se apresenta o raciocínio tocante à questão de pesquisa; (II) apresentar os materiais e métodos; (III) 
Transparência quanto à Arquitetura da Informação e Usabilidade: caso do portal da Assembleia Legislativa do Estado do Paraná

expor os dados; (IV) discutir os achados com a literatura e a (V) conclusão.

\section{Estrutura digital da Transparência}

Observações quanto ao emprego da Internet na política tal qual seus impactos na Democracia são encontrados na literatura com vários nomes como "democracia digital", "ciberdemocracia", "democracia eletrônica", "teledemocracia”, "democracia virtual” ou edemocracia (BRAGATTO, 2011). Entende-se por democracia digital "o emprego de tecnologias digitais de comunicação com o objetivo de corrigir, incrementar ou incorporar novos procedimentos ao processo político, no sentido de melhor atender a um ou mais princípios da democracia" (ALMADA; CARREIRO; BARROS; GOMES, 2019, p. 163). Todavia, a expressão "democracia digital" é pouco esclarecedora até que se distinga a ideia de democracia que a sustenta, pois, cada modelo, ou ênfase, tem uma ideia de como a Internet deve ser utilizada para estar a seu serviço (GOMES, 2011). Stabile complementa essa visão, e aponta que estudar Democracia Eletrônicaé entenderem que contexto as Tecnologias de Informaçãoe Comunicação beneficiam o ambiente político democrático e que tipo de benefício elas proporcionam assim como quem é o beneficiado (STABILE, 2012, p. 22), uma vez que a tecnologia não trará necessariamente soluções democratizantes, o que requer ainda todo um conjunto de ações e encaminhamentos de ordem propriamente política (SILVA, SANTOS, RABELO, LUCIANO, 2020).

A discussão sobre a relaçãoentre tecnologia e política não se limita aos sistemas políticos, mas também pode englobar a questão dos governos (CRUZ-RUBIO, 2015), principalmente relacionada à digitalização de informação (MARQUES; PEREIRA, 2015). Contudo, ressalta-se que a infraestrutura eletrônica não transporta simplesmente o fenômeno social, mas participa da sua produção (VENTURINI; BOUNEGRU; GRAY; ROGERS, 2018). As características da arquitetura de uma plataforma têm implicação direta no tipo de política de informação e comunicação que a permeia, sendo que a heurística da arquitetura digital aplicável a várias áreas da política de comunicação online (BOSSETTA, 2018). Ou seja, tais práticas não representam somente a digitalização de atividades do Estado, mas também ajudam a configurá-las.

O debate sobre transparência pública se relaciona com essa discussão, uma vez que ela é vista como uma agenda da democracia (PINHEIRO, 1991; MOISÉS, 2008). Todavia, como não existe um único modelo de democracia, (HELD, 1987), ela não é vista somente por uma perspectiva, nem com um único significado (GOMES, AMORIM, ALMADA, 2015). O conceito de transparência na teoria política foi precedido pela noção de "publicidade" (GOMES, AMORIM, ALMADA, 2018, p. 2), podendo ser entendido como aquilo que se permite ver e compreender a partir dos dados e das informações disponíveis, isso significa que decorre da abertura de dados e informações e, é utilizada para se falar da condição de exercício da autoridade pública sob o controle cognitivo alargado dos cidadãos e de instituições externas ao Estado 
(ALMADA; CARREIRO; BARROS; GOMES, 2019). Deduz-se, então, que transparência é mais do que a publicidade do ato, mas diz respeito à abertura e compartilhamento de informações, que torna o público mais capaz de decidir e fazer as escolhas políticas, aumenta a accountability e reduz o âmbito da corrupção (CAMPOS, PAIVA, GOMES, 2013).

Parte das pesquisas sobre a área se debruçam sobre as restrições ou potencialidades sobre a ideia. Sobre as potencialidades, sustenta-se que a transparência proporciona e dissemina informações sobre o governo (BERTOT, JAEGER, GRIMES, 2010, p. 267), apontam relevância dela para a credibilidade que as pessoas dão às instituições (FAIRBSANS et al., 2007), assim como a possibilidade de estimular esforços para aumentar o nível moral das instituições (MEIJER, 2009).

Entretanto, também se é dito que a transparência sozinha não é suficiente e que para ter significado real sendo necessárias as dimensões de avaliação e projeção (MARSH, 2011); que ela diminui o nível de confiança no governo, pois os cidadãos se sentiriam alienados das instituições governamentais e suspeitariam das práticas políticas, logo, alguns indivíduos ou grupos poderiam ganhar a confiança perdida, proporcionando uma nova questão de accountability (MARGETTS, 2011). Conclui-se que as potencialidades e limitações se relacionam diretamente com o que é considerado como transparência.

Ananny e Crawford (2016) apresentam uma tipologia das distintas compreensões presentes na literatura. Um primeiro significado leva em conta as informações que são disponibilizadas (se são confiáveis ou são divulgadas somente nominalmente). $\mathrm{O}$ segundo considera o tipo de prestação de contas possibilitada (encarrega a organização somente a responder ou apresenta o poder de sancionare exigir compensação por danos). Outra distinção pode ser observada quanto a direção em que as informações são disponibilizadas (vertical agentes internos de diferentes hierarquias conseguem observar a conduta uns dos outros, e horizontal - possibilidade de acessar as informações para além dos limites das instituições que as tutelam). A maneira pela qual se configura a transparência organizacional (o que é realizado é pontual ou se integra à rotina institucional) e a regularidade pela qual as informações são apresentadas (publicadas retrospectivamente ou sincronicamente) também servem como características distintivas.

Isto posto, percebe-se que as perspectivas dos trabalhos sobre transparência compartilham, em algum grau, a ideia enunciada por Ferracioli e Herman (2018) de que somente o cumprimento da legislação pelos entes federativos não implicará em ganhos democráticos se não vir acompanhada de um público que saiba usar as ferramentas, uma vez que a utilização dessas ferramentas pode ficar restrita a um grupo seleto de indivíduos, como jornalistas e servidores públicos. À vista disso, Marques (2016) sustenta que os métodos e estratégias para a configuração de mecanismos de transparência digital podem se beneficiar das descobertas já realizadas na área de e-participação, pois os níveis de transparência estão relacionados aos 
Transparência quanto à Arquitetura da Informação e Usabilidade: caso do portal da Assembleia Legislativa do Estado do Paraná

esforços e ao perfil dos técnicos de cada instituição, assim como aos objetivos inerentes a elas.

Nesse sentido, Noveck (2014) sugere que o design das telas pela qual as pessoas interagem com o governo é feito, provavelmente, para ser menos efetivo à participação dos cidadãos e produzir comentários que são menos gerenciáveis para os reguladores. Além disso, ela defende a necessidade de aqueles que entendeme se importam com a democracia também estarem envolvidos na criação da tecnologia caso o interesse seja o fortalecimento da democracia digital centrada no cidadão, ao invés de somente uma democracia digital centrada no cliente.

Ademais, a autora enfatiza que a criação de ferramentas de informação deve ter como premissas que (I) ao se fornecer informação, deve-se entregá-la em um formato útil aos destinatários; (II) nem todos os beneficiários são especialistas; (III) a informação é disseminada com sucesso entre as comunidades interessadas que, no que the diz respeito, repassarão aos seus membros; (IV) a informação deve estar vinculada ao contexto social de comunicação no processo de produção de regras; (V) aprimorar o uso da tela do computador facilitará a conexão com às pessoas envolvidas (NOVECK, 2004, p. 9). Tais ponderações estão relacionadas aos conceitos de arquitetura da informação e usabilidade.

Especificamente, quando se fala em arquitetura da informação, tem-se em mente a maneira como se organiza e apresenta a informação para que ela seja assimilada com facilidade, pois tem como principal objetivo atender às necessidades dos usuários de websites (CINNANTI, 2011). Em outras palavras, é possível compreender a arquitetura da informação com a lógica da disposição das informações em um determinado contexto, que abarca as decisões de onde e como dispor determinado dado. Por isso, conhecer a audiência (dimensão dos usuários) - como aborda as tarefas, que vocabulário utiliza e se a arquitetura existente faz algum sentido - se mostra fundamental para a área. Ou seja, saber, nem que minimamente, quem utilizará o produto é vital para a Arquitetura de Informação (CALDAS, 2007).

A preocupação com o utilizador motivou investigações de áreas de conhecimento distintas, o que proporcionou focos e contribuições diversas (CAMARGO, VIDOTTI, 2011). Camargo e Vidotti (2011) apresentam que dentre as diferenças de perspectivas marca-se a distinção entre o design de informação e o de interação. O primeiro foca no conteúdo, na apresentação dainformação paraf acilitar a compreensão do usuário, enquanto o segundo se atenta na relação do conteúdo como sistema, em definir a interação com as funcionalidades do ambiente. Assim, as autoras compreendem que a Arquitetura da Informação envolve ambos, já que se aborda tanto a forma de apresentação da informação apresentada pelo usuário, quanto a organização e a estrutura de dados. (CAMARGO, VIDOTTI, 2011).

Nesse contexto, a usabilidade pode ser entendida como "a capacidade de um sistema interativo oferecer ao usuário, em determinado contex to de operação, a realização de tarefas de maneira eficaz, eficiente e agradável" (SOUZA, 2009, p. 20). Então, enquanto a arquitetura da informação trabalha com o esquema mental ou organização lógica do que será of ertado, a 
usabilidade está preocupada com o produto/serviço em si, isso significa que a preocupação com usabilidade está contida no escopo da arquitetura da informação, mas que a última não se resume à primeira, já que a lógica de organização informacional não é abarcada pelos parâmetros de usabilidade.

Todavia, por mais que tenha emergido a preocupação com facilitar a interação do usuário com os sítios virtuais, nãose pode dizer que tais recursos sãoneutros já que a maneira de construir as informações, mostrá-las, ou mesmo acessá-las não é universal, mas relacionada com esquemas culturais (FRICK, 2008). Dito isso, pesquisas que abordam a transparência pela perspec tiva da arquitetura da informação e da usabilidade são importantes visto que muitas vezes a informação requerida está no portal, no entanto, o caminho para se chegar a ela é longo e não óbvio, o que dificulta sua localização. Há também casos em que o excesso de informação pode dificultar a etransparência, pois a localização daquilo que é do interesse do cidadão está disperso ou requer uma pesquisa avançada para que seja encontrada, o que torna árduo o processo de busca do cidadão (AMORIM; ALMADA, 2016, p. 66). Além de tudo, tem-se em mente ainda que sites de e-governo apresentam diversos problemas de usabilidade, como formatos inconsistentes, baixa capacidade de navegação e orientação (SCHNEIDER; OLIVEIRA; BARNI; FERREIRA; TEZZA, 2018).

Os esforços do governo brasileiro a fim de atender às demandas por mais transparência e participação na gestão pública são variados (promulgação de leis que consideram obrigatória a divulgação de dados, informações e ações do governo em tempo real através da internet; participação em parcerias que preveem a divulgação de dados e informações sobre o governo na internet para tornar governos mais transparentes e accountable), sendo que o desenvolvimento e reestruturação do Portal de Transparência do Governo Federal (para melhorar sua usabilidade e interatividade, etc.) é um dos compromissos assumidos pelo Brasil como parte do Plano de Ação Brasileiro na Parceria para Governo Aberto (SILVA, DOMINGUEZ, 2017).

Neste sentido, pode-se entender que as ações tomadas pelo governo como possibilidades de modificação da cultura institucional existente (ALVES, 2012) ou como meios de visibilidade para a espetacularização doprocesso democrático, aumentan do sua legitimidade perante a opinião pública, mas que eles somente cumprem a exigência legal de divulgação de informações (ABDALA; TORRES, 2016). Desse modo, entende-se que a transparência praticada institucional pode ser entendida alinhadaà perspectiva de Abdalae Torres, de focada meramente na divulgação de dados e documentos, ou mais próxima a Alves, quanto ao fomento à cultura do acesso. Na seção seguinte é apresentada a metodologia da pesquisa, de modo a responder à questão anteriormente elencada. 


\section{Material e Métodos}

Dado que a arquitetura da informação é um conceito que pode ser observada por muitas perspectivas, não existe uma única maneira de se analisá-la. Na investigação adota-se a técnica da observação sistemática para identificar a possibilidade de interação oferecida pelo sítio online e, consequentemente, observar a transparência praticada. Durante essa etapa, realizada através de um computador pessoal, no início de novembro de 2019, elaborou-se umpequeno diário de campo com anotações referentes às estruturas presentes em cada página junto aos elementos simbólicos percebidos na interação. Em seguida, tais dados foram ordenados de maneira a retratar a arquitetura das informações. A data de captura das telas se justifica pela modificação na estrutura do sítio online da instituição ocorridaem 14 de outubro de 2019, em fase de testes, e apresentação oficial no dia 18 de novembro de 2019 (BUDOLA, 2019).

Quanto à usabilidade, decidiu-se utilizar o método de inspeção, caracterizado pela utilização de conceitos e regras previamente estabelecidos para a identificação dos problemas de usabilidade nas interfaces, ou seja, o usuário não participa diretamente na avaliação. Dentre as técnicas possíveis, optou-se pela lista de verificação que consiste em um conjunto de regras baseadas em recomendações, aplicadas diretamente na interface. (SOUZA, 2009). A técnica é considerada mais eficiente na detecção de problemas de usabilidade do que os guias de recomendações genéricos (DIAS, 2006, p. 59); é uma das mais abrangentes quanto à quantidade e tipos de problemas identificados; além de ser a que permite maior repetitividade e reprodutibilidade; assim como ser a de mais fácil aplicação (CYBBIS; BETIOL; FAUST, 2010).

Decidiu-se adaptar a lista apresentada por Nascimento (2010) (108 enunciados), com a de Camargo e Vidottti (2011) e Caldas (2007), 49e 54 itens respectivamente, de maneira a agregar os elementos semelhantes e retirar os que se sobrepunham, bem como aqueles que Nielsen e Loranger (2007) verificaram já não apresentar impacto na usabilidade em decorrência da adaptação do usuário às plataformas ou a criação de padrões e convenções de design predominantes (cores que deveriam ser utilizadas ou evitadas, resolução das imagens, tempo de carregamento das páginas, especificações para os elementos multimídia, quantidade de clicks para alcançar o conteúdo nos sítios); assim como elementos que são presentes em sítios virtuais de naturezas diversas daquelas dos governamentais (presença de conteúdosde outros sites, seja como anúncios ou como buscadores que fazem a investigação na internet e não no interior do sítio, mas também apontamentos sobre serviço de bibliotecas, especificamente quanto a reservae devolução de material), o que resultou em uma lista com 47 pontos a serem verificados.

A inspeção da usabilidade se deu mediante a uma nova navegação, realizada ainda em novembro de 2019 em dia distinto da utilizada para observar os elementos simbólicos e arquitetura da informação. Tal ação foi tomada a fim de diminuir a influência de uma análise sobre a outra. A resposta à questão de pesquisa se dá pela descrição do sítio e a identificação de obstáculos durante a navegação no sítio online. Não se buscou medir a quantidade ou a grandeza 
de tais impedimentos, mas de observá-los frente ao conceito de transparência e assim buscar identificar se existe alguma intenção em facilitar a interação dos usuários com a plataforma. Na seção seguinte, apresentam-se os dados levantados pela observação sistemática e pela lista de verificação, junto com as situações que não conseguem ser abarcadas pelo método.

\section{Arquitetura do Portal da ALEP}

Observar a página inicial do sítio online é importante visto que é a forma em que o usuário, majoritariamente, iniciará seu contato como apontado por Nielsen e Loranger (2007). Porém, para o restante do portal, será feita uma descrição mais sucinta, dedicando maior atenção para a página referente a transparência.

Na página inicial do sítio online da ALEP(Figura 1) consta o logo estilizado da instituição ao lado do menu superior, composto pelas categorias "assembleia", "deputados", "atividade parlamentar", "legislação", "destaques" "infolep" e "transparência” (apresentadas de forma mais detalhada a seguir), além de um ícone para pesquisa (lupa). Abaixo ao menu encontram-se as notícias de cunho institucional em destaque à esquerda, margeadas por outros informes e seguida pelo atalho para a página dos deputados. 
Figura 1 - Pá gina inicial.

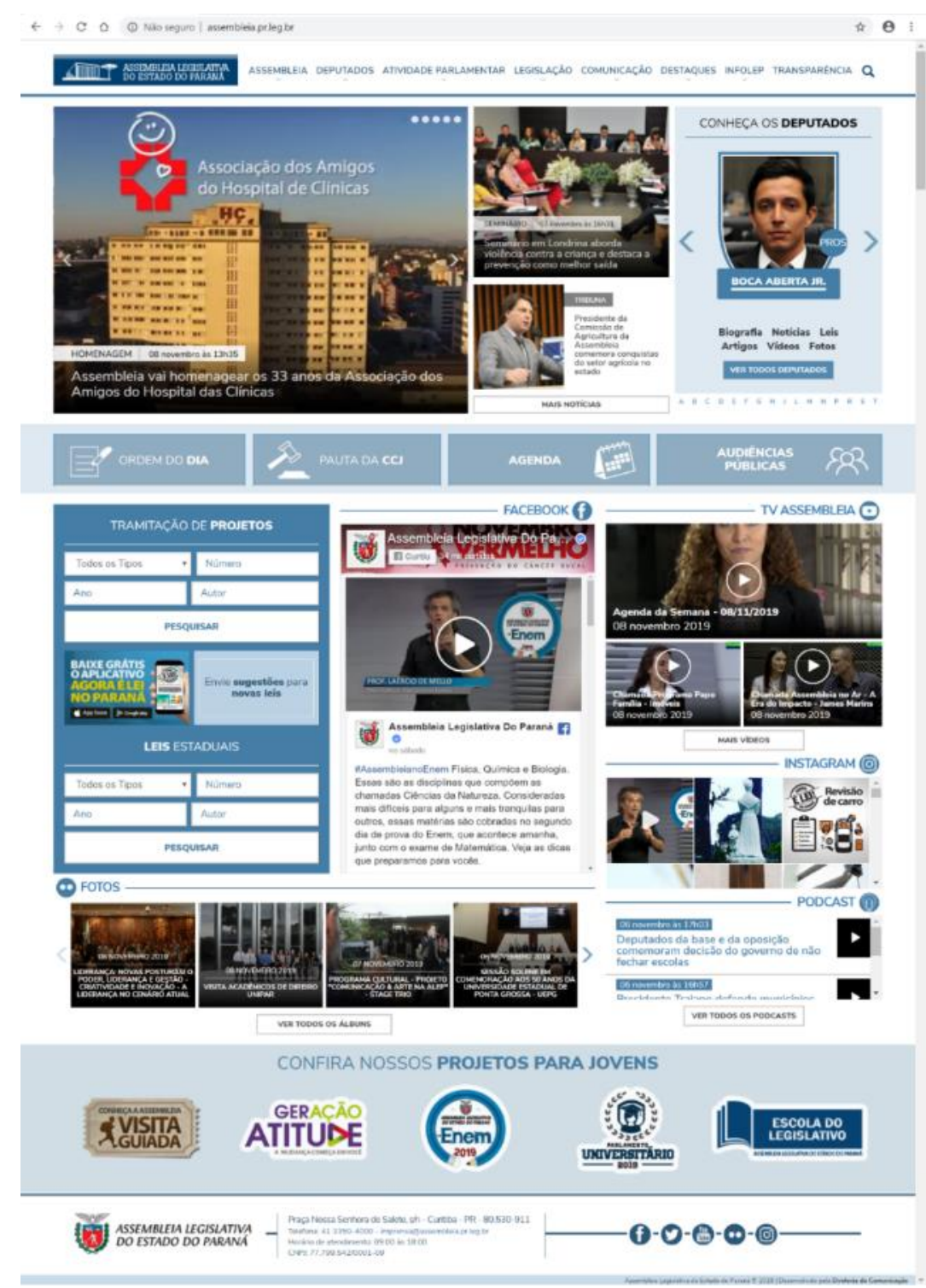

Fonte: Captura feita pela autora em 10 de novembro de 2019.

Na parte central constam direcionadores para a ordem do dia, pauta da Comissão de Constituição e Justiça, Calendário de atividades da instituição e audiências públicas; áreas de pesquisa sobre projetos legislativose leis estaduais, espaços de exposição das publicações nas plataformas digitais da instituição (perfil em redes sociais digitais como Facebook, Instagram e Flickr; assim como os vídeos da TV Assembleia hospedados no YouTube).

Segue-se com informações sobre os "projetos para jovens" (visita guiada, Geração Atitude, Assembleia no Enem, Parlamento Universitário e Escola do Legislativo), sendo que a Escola do Legislativo se dedica a fazer projetos cursos para a população em geral e capacitações para servidores ou agentes políticos. Encerra-se a página com o brasão oficial, informações para contato (endereço, telefone, horário de funcionamento), CNPJ e atalhos para as contas nas redes sociais digitais.

Na categoria "assembleia” é apresentada a história da instituição, as pessoas que 
ocuparam o cargo de Presidente e $1^{\circ}$ Secretário, em que ao clicar nas fotos é direcionado a páginas referentes à história, notícias, leis vídeos e fotos desses parlamentares; uma aba intitulada "conheça a assembleia" que corresponde à visita guiada à instituição e ao mapa do site, Figura 2. Curiosamente, no mapa do site, todas as categorias do menu superior são apresentadas junto com as subcategorias referentes com exceção à de "transparência".

Figura 2 - Mapa do sítio online.
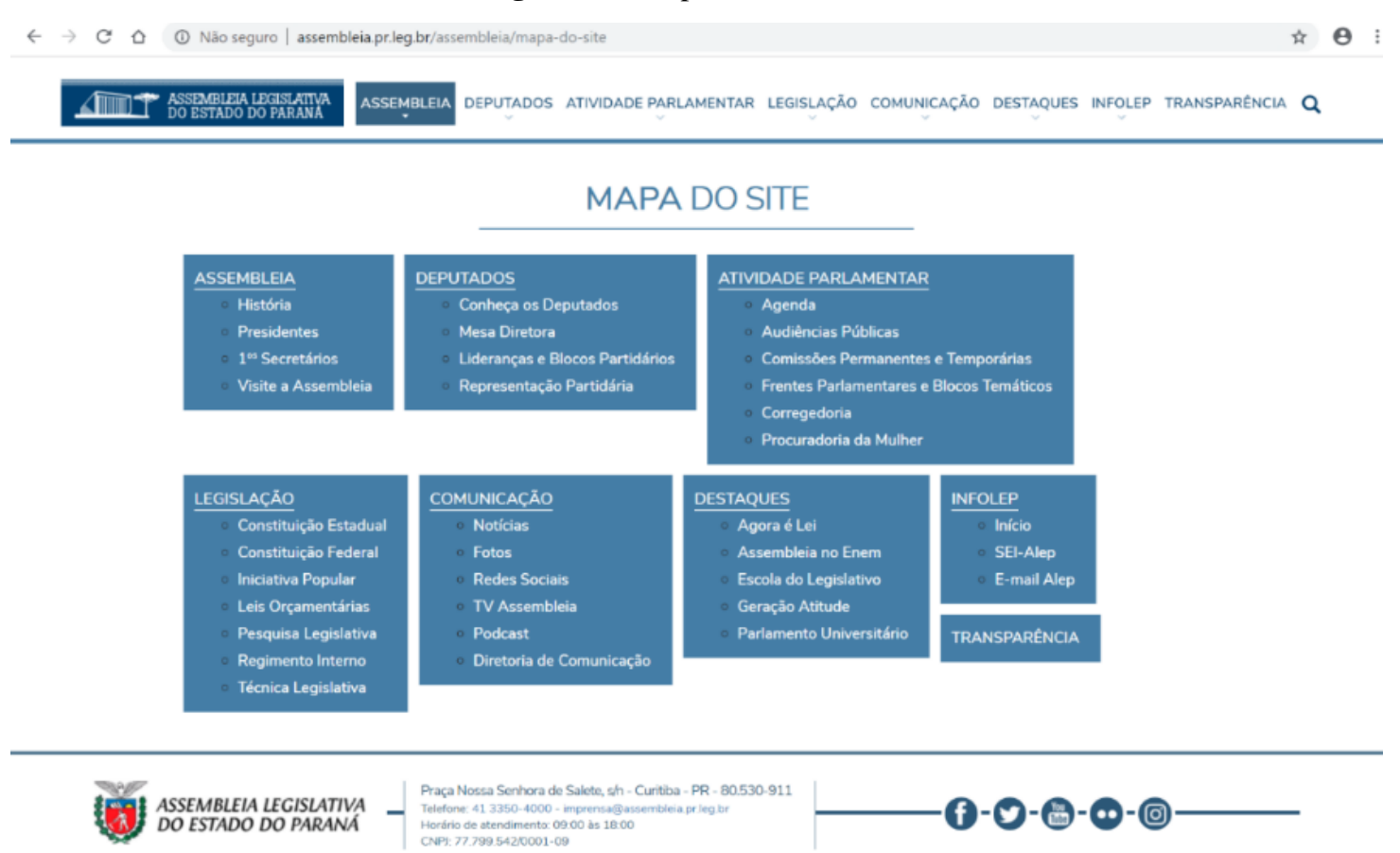

Fonte: Captura feita pela autora em 10 de novembro de 2019.

A categoria "deputados" é composta por "Conheça os Deputados", "Mesa Diretora", "Liderança e Blocos Partidários" e "Representação Partidária" apresenta os parlamentares que compõem a casa legislativa, a Mesa Diretora, os partidos, assim como aqueles que são líderes de partido ou blocos partidários.

Tirando o primeiro item - que consta as fotos de todos os deputados e está organizado com destaque aos membros da mesa (Presidente, $1^{\circ}$ Secretário e $2^{\circ}$ Secretário na primeira linha e os outros membros na segunda linha) sendo que os parlamentares restantes são apresentados em ordem alfabética - e o segundo que apresenta os deputados da mesa diretora na mesma ordem que o item anterior, as duas páginas restantes ordenam os parlamentares de forma não evidente.

$\mathrm{Na}$ "atividade parlamentar" constam a agenda geral do que ocorrerá na ALEP, assim como a agenda de audiências públicas com informações quanto a data e local; a composição e competências de cada comissão, frente parlamentar e bloco (situação que possibilitou a peculiaridade na parte das frentes parlamentares de ter a distinção quanto ao arquivamento delas sem apresentação de Relatório Final, indicada na Figura 3, o que acontece com as Comissões e 
não com as Frentes).

Figura 3 - Frentes parlamentares.

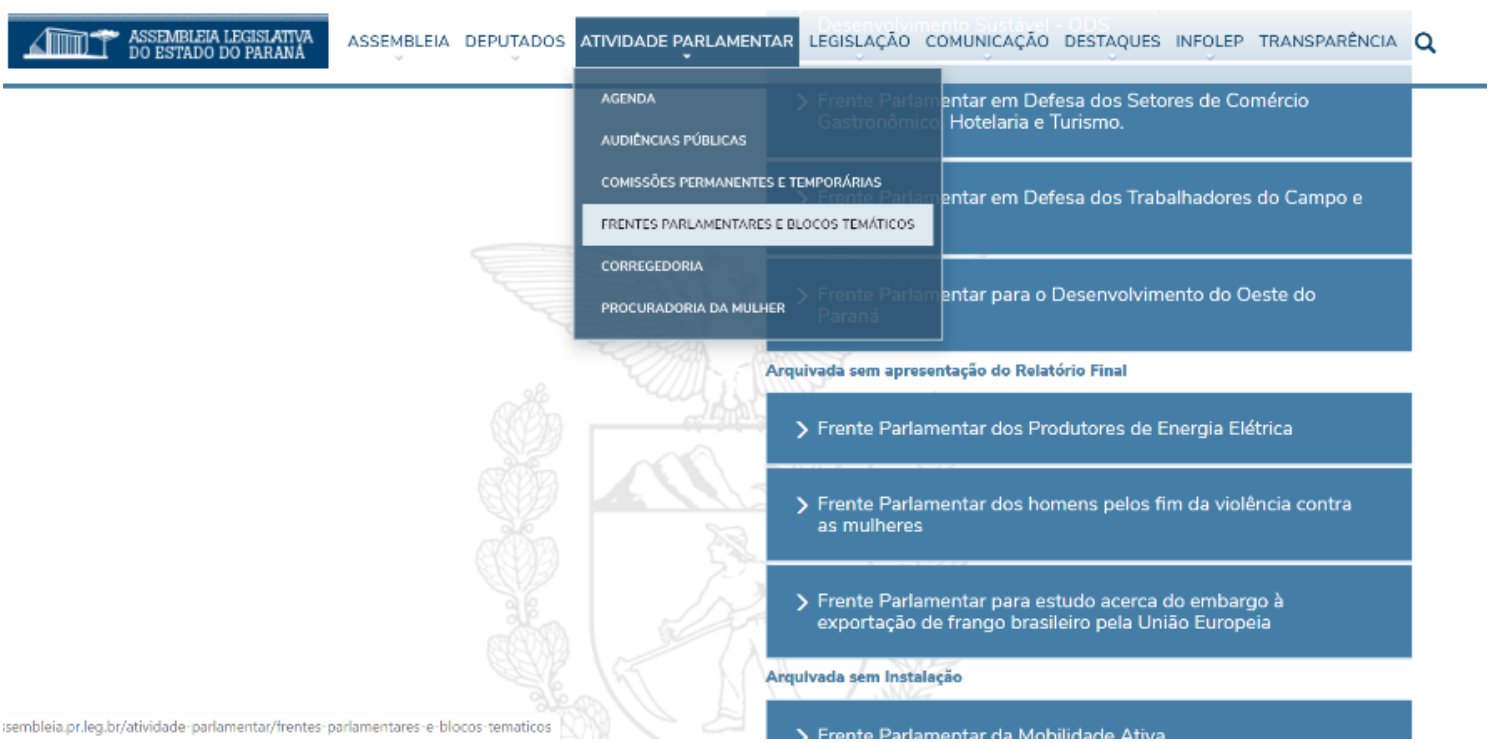

Fonte: Captura feita pela autora em 15 de novembro de 2019

Na seção também se encontram as páginas da Corregedoria e da Procuradoria da Mulher, em que se apresentam os parlamentares encabeçando tais postos e a descrição das atribuições. A Corregedoriaé responsável por garantir o cumprimento das determinações do Regimento Interno, do Código de Ética e do Decoro Parlamentar da Casa, assim como apurar denúncias aos parlamentares. Já a Procuradoria da Mulher é um órgão destinado à promoção de políticas públicas e defesa dos direitos femininos, mas também recebe denúncias de discriminação e violência contra a mulher. Na parte de atividade parlamentar ocorreu o estranhamento da pesquisadora que esperava algo relacionado à agenda dos parlamentares e atividades desenvolvidas pelos deputados, mas encontrou elementos ligados mais à instituição e às funções burocráticas, mencionados anteriormente.

No espaço referente à legislação, tanto a Constituição Estadual quanto a Federal são apresentadas em quadros que reproduzem as páginas em que os textos estão hospedados, Sistema Estadual de Legislação da Casa Civil e Planalto respectivamente. Por sua vez, a página de iniciativa popular apresenta as regras relacionadas e fornece um link para a Central de Atendimento ao Cidadão (CAC) como auxílio às possíveis dúvidas. Porém, tal link redireciona para uma página de erro, porque há divergência entre a URL colocada na página e a que corresponde a da página da CAC. A aba em questão também possibilita acessar os documentos das Leis Orçamentárias, realizar pesquisas legislativas, assim como acessar o Regimento Interno e obter informações quanto à técnica legislativa.

Em relação à "comunicação", apresentam-se as notícias publicadas no sítio online; amostras de fotos e de conteúdos publicados nas redes sociais ou na TV Assembleia. 
Especificamente, ao selecionar para ver todos os álbuns na aba das fotos, o usuário é levado para o perfil institucional no Flickr; fato semelhante ocorre na parte referente à TV Assembleia, só que o redirecionamento se dá para o YouTube. No caso do espaço nomeado como "podcast" constam notícias escritas com possibilidade de serem acompanhadas por áudio. Há também a apresentação do contato telefônico dos membros da diretoria de comunicação.

O redirecionemanto feito às redes sociais digitais não é recomendado, pois remete ao usuário à experiência de utilizar aquelas plataformas específicas que se valem de maneiras de interação e significados próprios e não necessariamente aplicáveis ao sítio online em questão. A situação pode ser entendida de maneira análoga à de quando os usuários utilizam, dentro dos sítios online, arquivos do estilo Adobe, Microsoft Word, Power Point, Excel e outros, nos quais o foco se dá na manipulação dos dados o que propicia facilmente o esquecimento de que se está em uma página online e ao término da utilização se é fechar a página, da mesma maneira como fazem ao utilizar o software originário (NIELSEN; LORANGER, 2007, p. 72). Nesse sentido, ao promover o redirecionamento para uma página terceira proporciona que o usuário utilize esquemas interpretativos de outras plataformas, se ele já tiver esse conhecimento, o que acarreta um tipo de interação para aquela página que pode não ser adequada.

Na categoria de "destaque”, são apresentados o aplicativo Agora é Lei, desenvolvidopela equipe de informática da instituição, os projetos Assembleia no Enem, Geração Atitude e Parlamento Universitário, além da Escola do Legislativo. De modo geral, nesse grupo são apresentadas as iniciatívas da ALEP em atuar para fora dos muros.

A aba "infolep" apresenta informações e interações destinadas aos funcionários da instituição, pois as três primeira subcategorias após o "início" (SEI, e-mail e sistemas) solicitam chave de acesso. Nesta seção também são apresentados os ramais telefônicos; o "entre nós" que se mostra um centro de notícias direcionado aos servidores. Também, há concentração dos comunicados e formulários de dicados à atividade relacionada à dinâmica institucional, além de apresentar uma parte de links úteis (calendário, e-protocolo, SIAF, menor preço, banco de preços, documentador, constituição federal e estadual, estatuto do servidor, regimento interno, decreto $52 / 84$ e organograma).

\subsection{Transparência no Portal}

Como citado anteriormente, as informações da parte destinada a transparência não são mencionadas no mapa do site, o que dificulta a pesquisa do usuário. Tal seção é composta, Figura 4, por “Compras e Licitações” (suprimentos e almoxarifado), "Receitas e Despesas" (subdividido em cartões corporativos, convênios, demonstrativo financeiro, verbas de ressarcimento, diárias de viagem, passagens aéreas, leis orçamentárias, plano de contas, relatório de gestão fiscal e balanço orçamentário), "Pessoal" (comissionados, estáveis, inativos, pensionistas, cedidos por outros órgãos, estáveis cedidos para outros órgãos, temporários e composição salarial dos 
servidores), "Plenário" (controle de votações, pesquisa legislativa e presença em plenário), “Atendimento ao Cidadão" e "Diários da Assembleia” (Diário oficial e diários anteriores a 2011).

Figura 4 - Portal da Transparência.

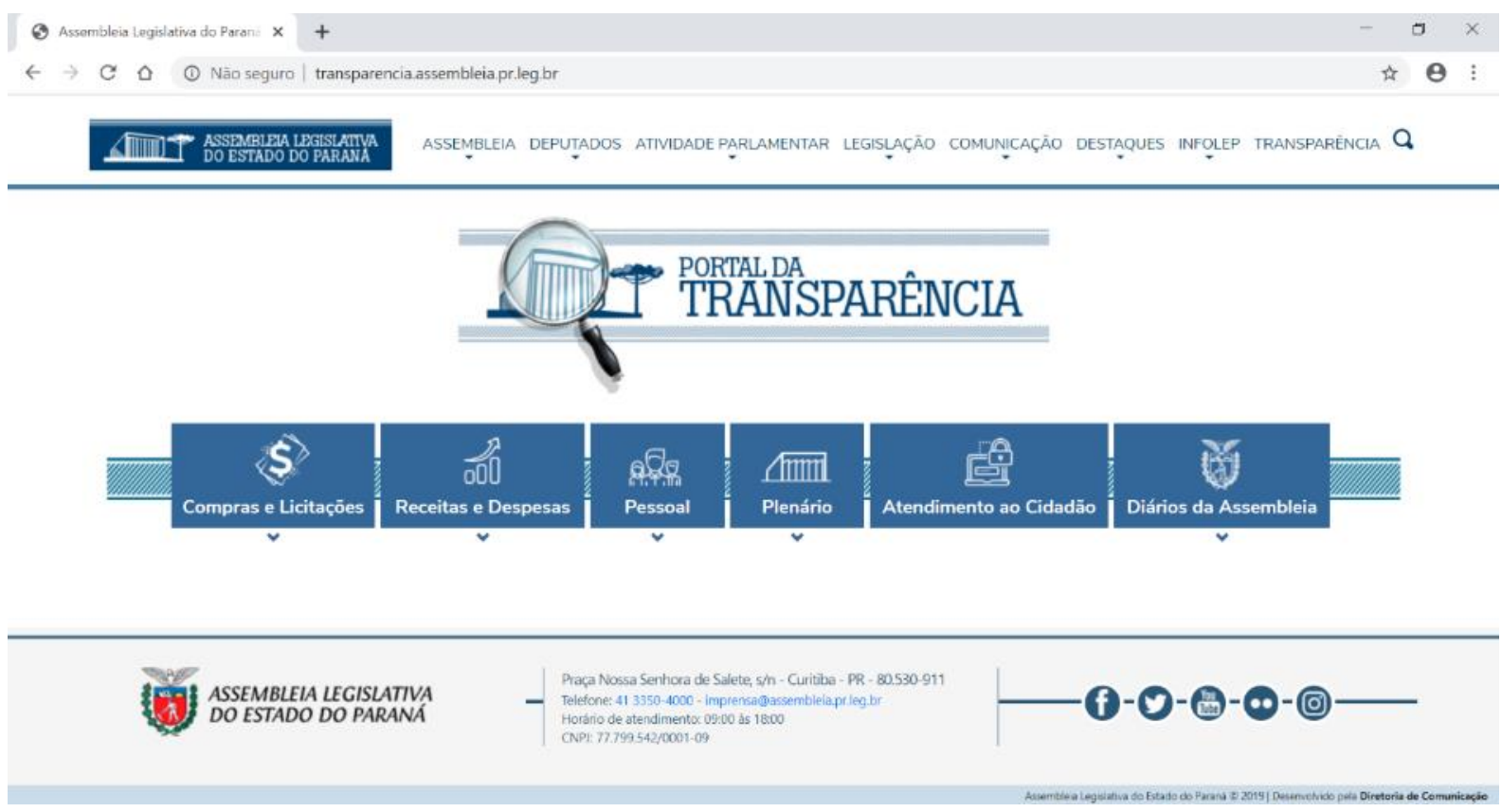

Fonte: Captura feita pela autora em 10 de novembro de 2019.

Os dados referentes às licitações, convênios, demonstrativo financeiro, verbas de ressarcimento, plano de contas, relatórios de gestão fiscal, balanços orçamentários e controle de votações são disponibilizados em PDF, formato que dificulta o trabalho com os dados e, por esse tipo de arquivo ter seu conteúdo geralmente como imagem, torna mais trabalhosa a busca por palavras-chave (NIELSEN; LORANGER, 2007). Poréma instituição aprovou uma resolução que prevê a disponibilização das informações em arquivos de formato aberto, o que solucionaria a situação (ALEP, 2019). Uma situação complicada observada no caso dos demonstrativos financeiros é que ao se buscar os valores referentes ao período anterior a 2014 não foi possível acessar os dados.

A apresentação dos dados sobre o controle de estoque, as diárias de viagem, passagens aéreas, pessoal e presença em plenário é feita por meio de tabelas dentro das respectivas páginas. Destaca-se que no caso da composição salarial anterior a 2014 é necessário digitar o nome da pessoa que se busca a informação, o que impossibilita o acesso às informações caso o usuário não busque dados sobre uma pessoa específica ou mesmo caso erre a escrita do nome em questão. Outro momento de dificuldade de acesso às informações ocorre quanto as presenças dos parlamentares no período anterior a 2014. Ao ser redirecionado para a página que apresenta esse conteúdo é possível selecionar o período desejado, em um primeiro momento mês e ano, seguida pelo dia que houve sessão plenária. Dentre as opções para o mês de referência, é possível 
selecionar de janeiro de 2011 até novembro de 2019, porém os dados só se mostram disponíveis entre março de 2011 e dezembro de 2013.

A penúltima seção do Portal da Transparência é o espaço destinado ao atendimento ao cidadão (Figura 5), que concentra as perguntas frequentes dos usuários e um formulário para caso deseje alguma outra informação. Nota-se que antes das perguntas está o seguinte aviso: “As solicitações enviadas para a Central de Atendimento ao Cidadão podem ser respondidas em um prazo de até 20 (vinte) dias, prorrogável por mais 10 (dez) dias. Assim que a informação estiver disponível, será enviada para o e-mail do solicitante" (grifo meu). Destaca-se tal passagem e grifo visto que a LAI, quanto aos prazos de resposta, em seu artigo 11 apresenta que:

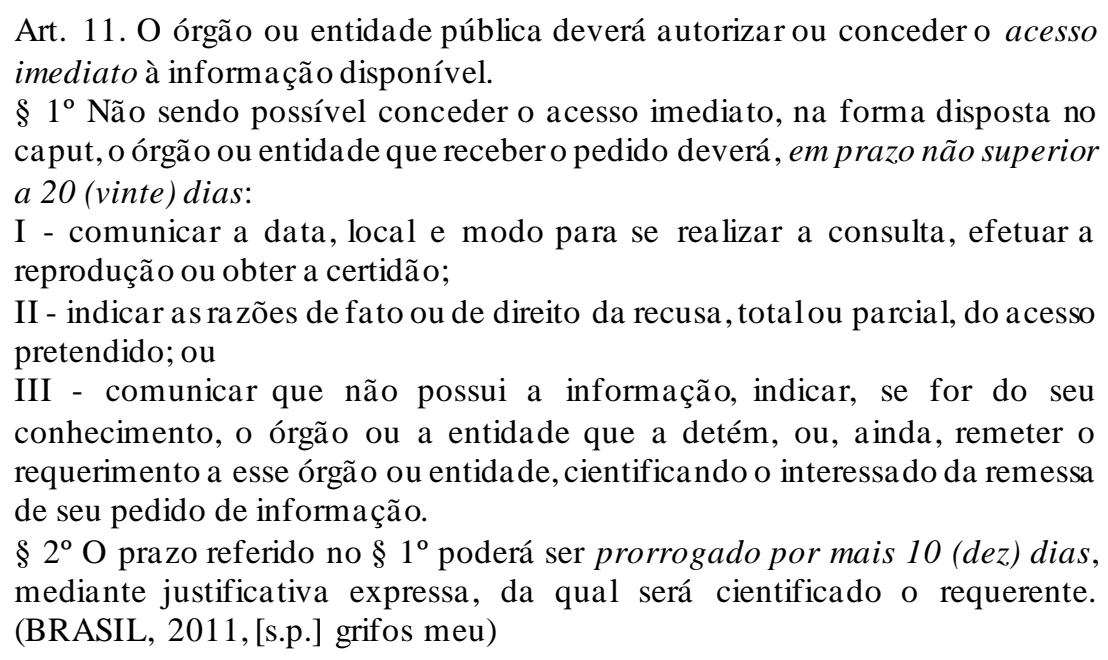

Dessa forma, o sentido passado pela ALEP ao utilizar o termo "podem" se mostra ambíguo, uma vez que não indica nem se as informações serão repassadas antes ou depois do prazo estipulado, o que nas matérias legais de referência federal (LAI) e estadual (decreto $\mathrm{n}^{\circ}$ 10.285/2014) é taxativa à obrigatoriedade de resposta ou disponibilização de acesso em um prazo inferior ou igual a vinte dias, possível de prorrogação expressa pelo órgão ao requerente. 
Figura 5 - Atendimento a o cidadão.

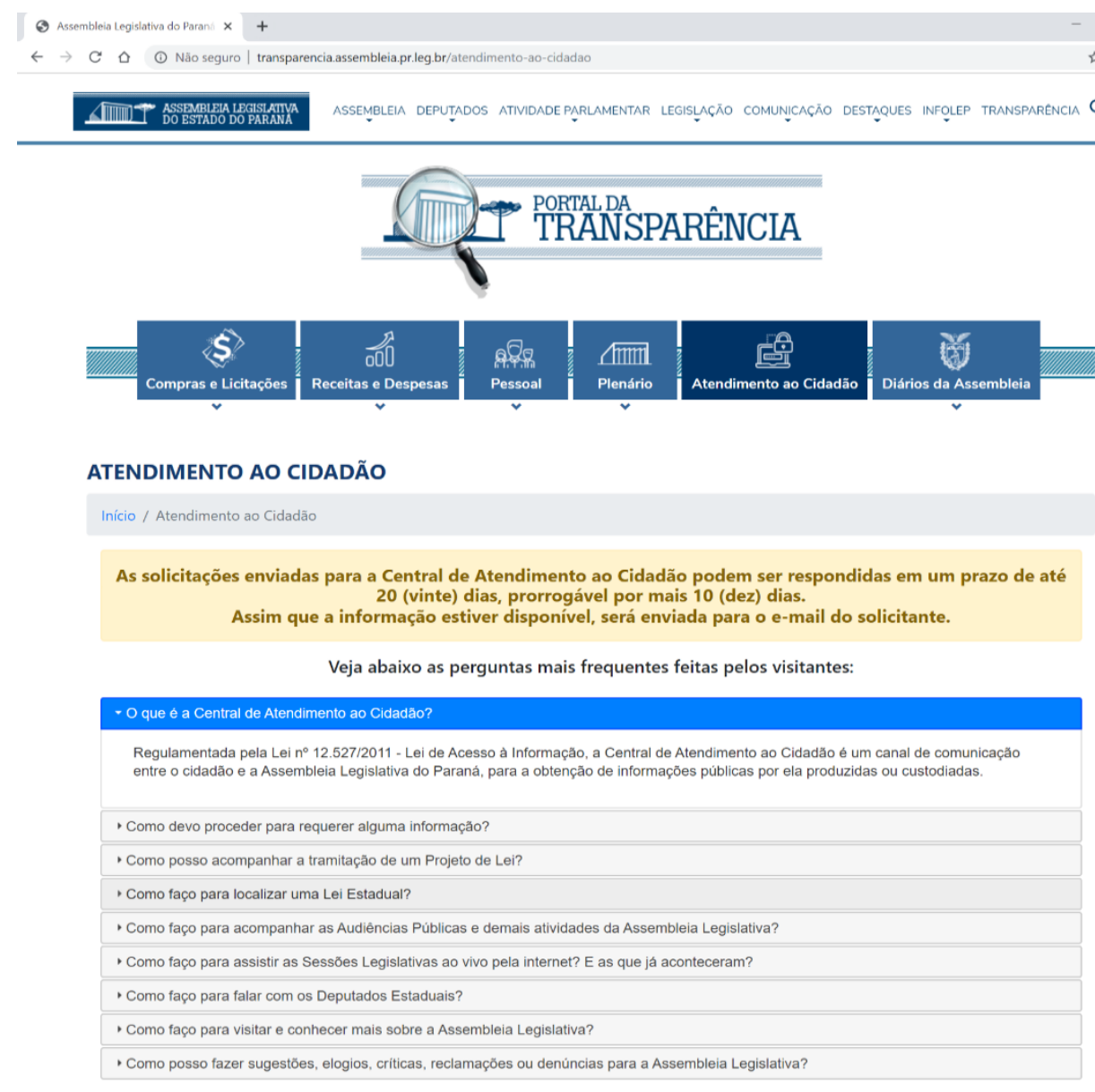

Não teve a sua dúvida esclarecida com as respostas acima? Utilize o formulário abaixo e envie a sua pergunta.

Selecione o Departamento:

- Central de Atendimento ao Cidadão - Lei de Acesso à Informação

Ouvidoria

Nome

Nome

E-mail

E-mail

Telefone

Telefore

Data Nascimento

Data Nascimento

CPF

CPF

Mensagem

Mensagem

I. ASSEMBLEIA LEGISLATIVA
DO ESTADO DO PARANA

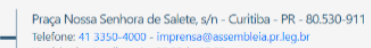

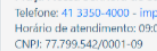

Q 
Sem se debruçar sobre os critérios de usabilidade propriamente ditos (etapa posterior), menciona-se que a seleção do departamento que receberá a mensagem (Central de Atendimento ao Cidadão ou Ouvidoria) na prática correspondem a um único setor a Ouvidoria e interno a ela encontram-se servidores responsáveis por lidar com os pedidos destinados à Central de Atendimento ao Cidadão. Além disso, como o formulário somente envia as respostas para a instituição e não abre um sistema para acompanhamento da mensagem, isso dificulta para o cidadão realizar possíveis pedidos de recursos.

O último tópico apresentado no menu é quanto aos diários da Assembleia. Ao selecionar o Diário Oficial aparece a mensagem de alerta “Sua conexão não é particular”, o que não é sanado com a troca de navegador (Google Chrome e Internet Explorer), só sendo possível o acesso pelo Firefox. Já quanto aos diários anteriores a 2011, verifica-se que permite a busca por dois mecanismos distintos (especificando um período e navegação entre as páginas com os documentos), sendo que os arquivos são disponibilizados em formato zip e após descompactação apresentam-se em PDF, o que remonta a discussão sobre o trabalho com os dados. Ademais, verifica-se que a página dos diários muda da área de "transparência" para a de "atividades parlamentares", espaço que não apresenta tal conteúdo na divisão das subcategorias do menu, como é possível ver na parte superior da Figura 6. 
Figura 6 - Diários anteriores a 2011.

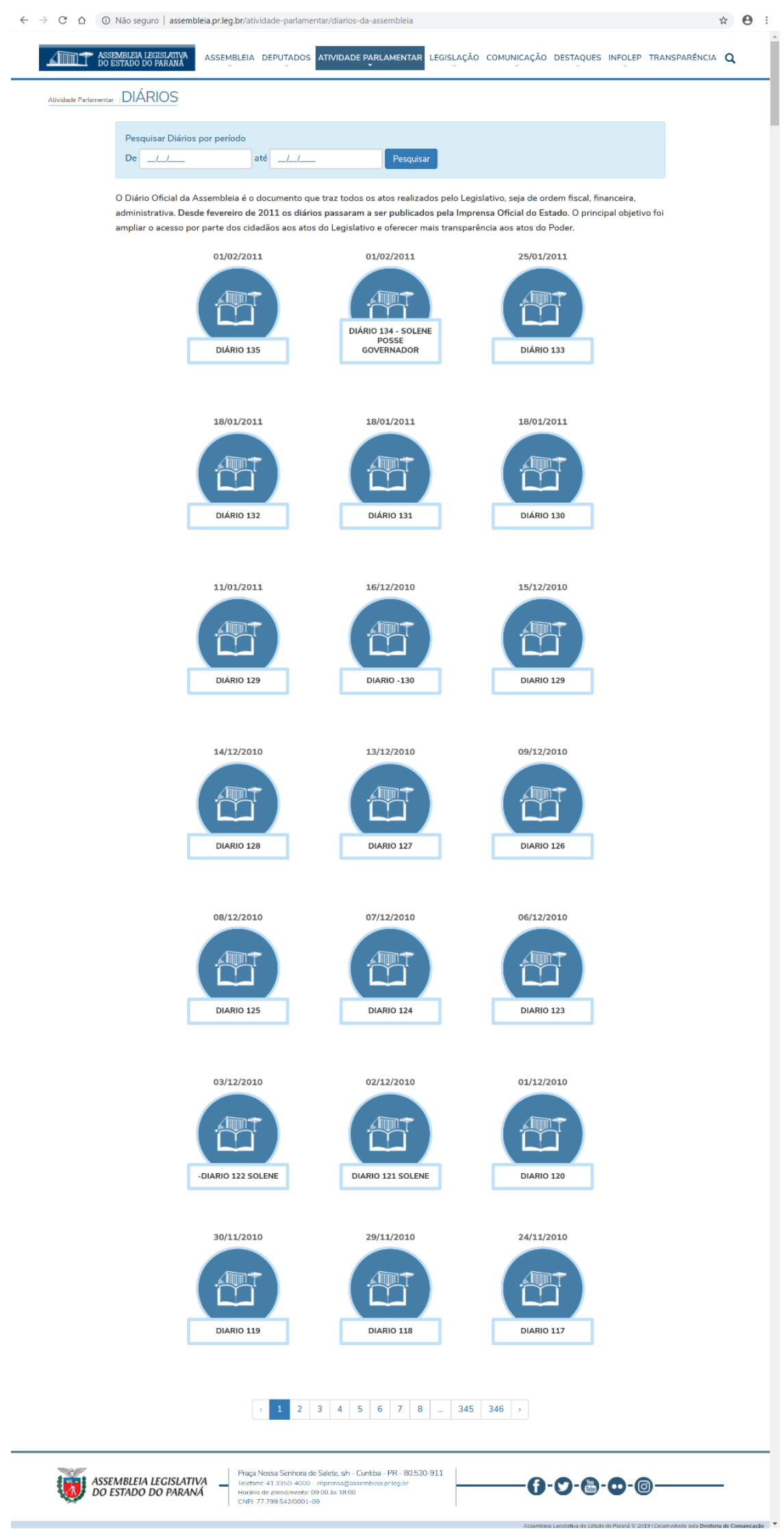

Fonte: Captura feita pela autora em 16 de novembro de 2019. 
As dificuldades de acesso aos diários no ambiente virtual, rememoram o ocorrido em 2010 sobre os Diários Secretos da Assembleia (KOHLBACH, BREMBATTI, ALBERTI, TABATCHEIK, 2010). A série de reportagens da Gazeta do Povo (2010) apura 2178 atos que nunca foram publicados em Diário Oficial, ocorridos entre janeiro de 2006 e março de 2009.

Desse modo, pode-se entender que esse tipo de conteúdo não é prioritário para a instituição. Isso porque, caso fosse, considera-se que não seria observada a situação apontada pela pesquisa. Contudo, pode ser o caso também, de os diários serem considerados importantes, mas se deseja dificultar o acesso a eles de alguma maneira. Para entender qual interpretação é a mais adequada se mostram necessárias maiores investigações.

\subsection{Lista de Verificação}

Os quadros presentes no apêndice apresentam os quesitos de avaliação, características ou explicações sobre elementos presentes nos enunciados para diminuir possíveis dúvidas quanto a metodologia, observações sobre usabilidade, a verificação do quesito e a avaliação quanto à conformidade às expectativas às características listadas, sendo conformidade (1) ou divergência (0). Faz-se necessária a coluna de avaliação porque as característicasexpressas pelos quesitos não apresentam somente aspectosesperados nos sítios online, pois preferiu-se não alterar a construção de alguns quesitos para não dificultar o entendimento.

Dentre os itens listados, verificou-se 28 pontos em conformidade, 19 contrários e um não aplicável. A fim de detalhar melhor os achados, debruça-se sobre as situações nas quais as disposições elencadas não conseguem abarcar a realidade transmitida pelo dispositivo da ALEP. O primeiro momento é a mudança de layout, que é importante tanto para o carregamento da página, na identificação do usuário, como na permanência dele no local desejado (NASCIMENTO, 2010), e por ela informar ao cidadão onde ele está, a mudança dessa estrutura durante a navegação, provoca perturbação na utilização. Tal situação ocorre no Infolep e nas páginas da categoria "Destaques".

O caso do Infolep pode ser entendido como uma demarcação de que tal área não seria destinada ao público geral, mas a um determinado conjunto de utilizadores, no caso os servidores da instituição. Já as páginas sob a rubrica "Destaques", verifica-se que são programas ou estruturas independentes entre si (exceto o Parlamento Universitário e Escola do Legislativo que apresentam integração estrutura que permite a página de um acessar a do outro), sendo que a estrutura do "Assembleia no Enem” se mostra muito pesada devido a elementos multimídia que não ajudam a interação.

Tal mudança também ocorre nas páginas das comissões e frentes parlamentares, em que o fundo branco sólido passa a apresentar o brasão oficial da instituição como marca d'água, o que aproxima tais informações da perspectiva institucional do que propriamente atividade dos 
parlamentares, parte da observação feita no primeiro quesito da tabela 6 do apêndice. Os outros fatores que demonstram caráter mais institucional do que foco nas atividadesem si é que a agenda mostrada reflete as ações que ocorrerão na instituição (seja visita de alunos de um colégio, seja grande expediente) e não a agenda dos parlamentares individualmente. No caso das audiências públicas, Corregedoria e Procuradoria da Mulher predomina o caráter informativo institucional, de modo a apresentar a data e local das audiências ou as atribuições dos respectivos cargos.

Cabe apontar que a organização do sítio faz pouco sentido para um agente externo, dadas as dificuldades na (i) organização da página de lideranças e composição partidária, na qual as informações não são apresentadas de maneira intuitiva (ordem alfabética ou quantidade de membros por partido), (ii) quando se utilizam os termos "Representação Partidária" para indicar a composição dos partidos na casae "Transparência" para tratar de assuntos diversos (documentos relacionados ao financeiro da ALEP, controle da presença e votação dos parlamentares, pesquisa sobre matérias legislativa, diários da instituição e o atendimento ao cidadão), apontamento realizado no item 20.

Por fim, ressalta-se a não disponibilização de serviços de informação para pessoas com deficiência no sítio online da ALEP, tendo em vista que no Censode 2010, 21,4\% dos paranaenses declaram possuir algum nível de deficiência visual, auditiva, motora e/ou intelectual (KOWALSKI, 2019). Tem-se em vista que a primeira transmissão pela TV Assembleia da sessão plenária realizada com intérprete de libras foi feita dia 5 de agosto de 2019 (FONTANA, 2019), mas que tal preocupação não foi levada para o sítio online até o momento da presente pesquisa.

\section{Discussão}

A partir dos dados, retomam-se à questão de pesquisa, cujo questionamento é quanto à como é praticada a transparência pela instituição através do sítio virtual. Através dos achados referentes ao Portal de Transparência da ALEP, identificaram-se problemas na arquitetura da informação, principalmente à ordenação lógica das informações, sendo questionado o agrupamento de informações sob determinados temas, assim como a utilização de termos ambíguos para as seções. Quanto à usabilidade, identificou-se que a instituição segue a maior parte dos quesitos listados, todavia há falta de homogeneidade no layout da instituição e pouca atenção aos cidadãos com deficiência. Desse modo, a pesquisa parece corroborar com a perspectiva dos autores com visão pragmática sobre transparência, de que por mais que haja ponderações legais sobre usabilidade na legislação referente, na prática essa preocupação não se mostra central, visto a disponibilização de vários dados sobre as atividades institucionais; mas com certos pontos em desacordo com a legislação, como no alerta anterior às perguntasf requentes na página de atendimento ao cidadão ou no problema quanto a disponibilização dos demonstrativos financeiros anteriores a 2014.

Por mais que a instituição venha tomando uma série de medidas com o discurso de 
"aumento da transparência" como no compartilhamento do Sistema Eletrônico de Informações (SEI) com o Tribunal Regional Federal da $4^{\mathrm{a}}$ Região (TRF4) (BUCHI, 2019); ou quanto a resolução número 21 de 2019, que implementa a obrigação da disponibilização de informações em formato aberto, não se pode ver tais iniciativas como visando a vanguarda no que se concebe sobre transparência, já que não são novas as propostas de mecanismos de avaliação de usabilidade e arquitetura da informação (e.g. NASCIMENTO, 2010; CAMARGO, VIDOTTTI, 2011; CALDAS, 2007; NIELSEN, LORANGER, 2007), mesmo em para sites governamentais (e.g. AMORIM, ALMADA, 2016).

Os resultados da análise de usabilidade e o próprio funcionamento da página de Atendimento ao Cidadão parecem corroborar a visão de Noveck (2004) de que o design das telas pela qual as pessoas interagem com o governo é feito, provavelmente, para ser menos efetivo e produzir comentários que são menos gerenciáveis para os reguladores. Nesse sentido, pode-se afirmar que as práticas da instituição se focam mais no fornecimento autônomo de informação (transparência ativa) do que no processo relacionado às solicitações pela Central de Atendimento ao Cidadão (transparência passiva).

Logo, mostra-se necessário investigar os fatoresque influenciam o nível de transparência, sejam (i) fatores pessoais, convicções; (ii) fatores organizacionais, como impacto administrativo, missão da agência, estrutura de comunicação ou a política interna; bem como (iii) recursos, especificamente tempo, pessoal e dinheiro (FAIRBANKS, PLOWMAN, RAWLINS, 2007). Nesse sentido, o apontamento de Frick (2008, p.83) de que não se pode dizer que tais recursos são neutros, sintetiza os resultados do trabalho, visto que a construçãodas ferramentas de maneira mais acessível ao cidadão não depende exclusivamente da questão econômica do Estado, mas de outras circunstâncias envolvidas. Deste modo, questiona-se a perspectivade Alves (2012) em que a LAI e as medidas legislativas correlatas possibilitaram uma modificação da cultura institucional existente, já que o caso da ALEP aparenta estar muito mais próximo de uma digitalização do processo como apresentado por Marques e Pereira (2015), do que de umareal mudança da cultura institucional.

Além disso, como aponta Gomes (2011) todo desenho de dispositivos, aplicativos, ferramentas para um portal ou sítio político pressupõe, antes de tudo, um conceito de democracia digital; ademais, por trás dela há, no que lhe concerne, um modelo de democracia. Em outras palavras, também não se pode afirmar que a perspectiva de Abdala e Torres (2016) quanto ao portal ser somente um meio de espetacularização visto que tais ferramentas compreendem um conceito de transparência, de democracia digital e consequentemente de democracia.

\section{Considerações Finais}

A partir da presente pesquisa percebe se que o sítio virtual da ALEP apresenta muitas possibilidades para aprimoramento no que se refere à Arquitetura da Informação e Usabilidade. 
Tais pontos, se trabalhados minuciosamente com os usuários, podem aperfeiçoar a transparência praticada pela instituição e consequentemente impactar na cultura democrática dos cidadãos, como ocorre nas redes sociais da CGU, identificado por Kniess (2019).

Isso posto, sublinha-se que a presente pesquisa não averiguou a usabilidade pela perspectiva dos usuários (SOUZA, 2009). Além disso, a autora de pesquisa não representa a totalidade de usuários do sítio virtual da Assembleia. Todavia, os achados e descobertas apontadas pela investigação são importantes visto que foi feita uma análise sistemática do caso. Ademais, corrobora-se com a perspectiva de Noveck (2004) quanto a importância do envolvimento daqueles que entendem e se importam com a democracia aos tecnólogos na criação da tecnologia para que assim ela seja centrada no cidadão, ao invés de somente centrada no cliente.

Em outras palavras, a pesquisa ajuda a defendera importância de se estudaros fenômenos relacionados à política de maneira conjunta ou relacionada às outras áreas de conhecimentos, visto a possibilidade de enriquecimento dos saberes, aprimoramento das ferramentas e ampliação da área de interpretação da Ciência Política. Nesse sentido, o trabalho serve como um exemplo, dentro da Ciência Política, enquanto que as investigações de Lauriberto de Souza Brasil (2016) e Cristina Cinnanti (2011) fazemesse papel nas áreas da Comunicação Públicae da Gestão Pública.

Têm-se consciência das limitações da ferramenta de lista de verificação, dentre elas, principalmente quanto a dificuldade em estabelecer graus de importância ou severidade entre as diferentes recomendações (DIAS, 2006). Entretanto, tal apontamento indica áreas a serem exploradas por pesquisas futuras, com metodologia complementares. Deste modo, o pre sente trabalho também serve como um apontamento inicial para objetos a serem pesquisados.

Trabalhos futuros podem se valer dos achados na presente pesquisa e se dedicar a entender com maiores detalhes o processo interno de transparência, assim como nos valores que influenciam a elaboração e manutenção dos portais institucionais dos poderes políticos. Além disso, se mostra necessário compreender a visão que os agentes das instituições têm sobre transparência, pois tais perspectivas podem indicar elementos importantes para a política de transparência que não são apreendidos pela literatura, visto as variações locais e culturais de cada órgão.

\section{Referências}

ABDALA, Paulo Ricardo Zilio; TORRES, Carlos Marcos Souza de Oliveira e. A Transparência como Espetáculo: uma análise dos portais de transparência de estados brasileiros. Administração Pública e Gestão Social, v.8, n. 3, p. 147-158, 2016.

Associação das Emissoras de Radiodifusão do Paraná (AERP). Estudo indica que 82\% dos paranaenses querem conhecer melhor o Legislativo Estadual. Disponível em: $<$ https://aerp.org.br/novo/associados/estudo-indica-que-82-dos-paranaenses-querem-conhecermelhor-o-legislativo-estadual/>. Acesso em: 6 abr. 2019.

ASSEMBLEIA amplia transparência e publicará tudo no Portal. ALEP. Disponível em: < 
http://www.assembleia.pr.leg.br/comunicacao/noticias/assembleia-amplia-transparencia-epublicara-tudo-no-portal-da-assembleia>. Acesso em: 15 nov. 2019.

ALMADA, M. P.; CARREIRO, R.; BARROS, S. R.; GOMES, W. da S. Democracia digital no Brasil: obrigação legal, pressão política viabilidade tecnológica. MATRIZes, v. 13,n. 3, p. 161181, 2019. DOI: 10.11606/issn.1982-8160.v13i3p161-181. Disponível em: https://www.revistas.usp.br/matrizes/article/view/158411. Acesso em: 24 out. 2020.

ALONSO, Thiago. Assembleia recebe propostas para prestação de serviços de publicidade institucional.

ALEP.

Disponível em:

http://www.assembleia.pr.leg.br/comunicacao/noticias/assembleia-recebe-propostas-paraprestacao-de-servicos-de-publicidade-institucional>. Acesso em: 29 dez. 2019.

ALVES, Marília Souza Diniz. Do sigilo ao acesso: análise tópica da mudança de cultura. Revista do Tribunal de Contas do Estado de Minas Gerais. Belo Horizonte, v. 1, n. 1, p. 120-134, 2012.

AMORIM, Paula Karini; ALMADA, Maria Paula. E-transparência: proposta de modelo metodológico para avaliação de portais de executivos nacionais. LOGOS 45, v. 23, n. 2, 2016.

AMORIM, Paula Karini Dias Ferreira. Democracia e Internet: a transparência de gestão nos portais eletrônicos das capitais brasileiras. 2012. Tese (Programa de Pós-Graduação em Comunicação e Cultura Contemporânea) - Faculdade de Comunicação, Universidade Federal da Bahia.

ANANNY, Mike; CRAWFORD, Kate. Seeing without knowing: Limitations of the transparency ideal and its application to algorithmic accountability. New Media \& Society, v. 20, n. 3, p. $973-$ 989, 2018.

BERTOT, John C.; JAEGER, Paul T.; GRIMES, Justin M. Using ICTs to create a culture of transparency: E-government and social media as openness and anti-corruption tools for societies. Government Information Quarterly, v. 27, n. 3, p. 264-271, 2010.

BOSSETTA, Michael. The digital architectures of social media: comparing political campaigning on Facebook, Twitter, Instagram, and Snapchat in the 2016 U.S. election. Journalism \& Mass Communication Quarterly, v. 95, n. 2, p. 1-26, 2018.

BRAGATTO, Rachel Callai. Democracia e internet: apontamentos para a sistematização dos estudos da área. Revista Compolítica, v. 1, n. 2, p. 132-163, 2011.

BRASIL, Lauriberto Carneiro Pompeu de Souza. A transparência do legislativo na era da comunicação digital: um estudo sobre os portais da assembleia legislativa do Ceará e da câmara municipal de Fortaleza. 2016. Monografia (Curso de Comunicação Social/Jornalismo) - Instituto de Cultura e Arte, Universidade Federal do Ceará, Fortaleza.

BRASIL. Lei $\mathbf{n}^{\circ} \mathbf{1 2 5 2 7}$, de 18 de novembro de 2011. Regula o acesso a informações previsto no inciso XXXIII do art. 5o, no inciso II do § 30 do art. 37 e no § 20 do art. 216 da Constituição Federal; altera a Lei no 8.112, de 11 de dezembro de 1990; revoga a Lei no 11.111, de 5 de maio de 2005, e dispositivos da Lei no 8.159, de 8 de janeiro de 1991; e dá outras providências. Disponível em: <http://www2.camara.leg.br/legin/fed/lei/2011/lei-12527-18-novembro-2011611802-publicacaooriginal-134287-pl.html>. Acesso em: 10 set. 2018.

BRASIL. Ministério a Transparência, Fiscalização e Controladoria-Geral Da União. $3^{\circ}$ Plano de Ação Nacional. Brasília: 2016. Disponível em: $<$ http://governoaberto.cgu.gov.br/noticias/2017/3o-plano-de-acao-nacional-na-parceriapara-governo-aberto/plano_port_web-3.pdf>. Acesso em: 9 set. 2018.

BUCHI, Maria Eduarda. ALEP e TRF4 assinam termo de cooperação para compartilhamento de sistema eletrônico. ALEP. Disponível em: $<$ http://www.assembleia.pr.leg.br/comunicacao/noticias/alep-e-trf4-assinam-termo-decooperacao-para-compartilhamento-de-sistema-eletronico>. Acesso em: 17 nov. 2019. 
BUDOLA, Trajano. Portal da Assembleia Legislativa, um dos mais modernos do Brasil, será lançado oficialmente na segunda-feira (18). ALEP. Disponível em: $<$ http://www.assembleia.pr.leg.br/comunicacao/noticias/portal-da-assembleialegislativa-estreia-entre-os-mais-modernos-dobrasil?fbclid=IwAR0mhyZeoGag9dN8suZm2afRwo8axx3xa1DImQeHNtqqbKT0gp2p o2MkFxU>. Acesso em 14 nov. 2019

CALDAS, Luiz Carlos Agner. Arquitetura de Informação e Governo Eletrônico: Diálogo cidadãos-Estado na World Wide Web - estudo de caso e avaliação ergonômica de usabilidade de interfaces humano-computador. 2007. Tese (Doutorado em Design) - Pontifícia Universidade Católica do Rio de Janeiro, Rio de Janeiro.

CAMARGO, Liriane Soares de Araújo de; VIDOTTI, Silvana Aparecida Borsetti Gregorio. Arquitetura da Informação: Uma Abordagem Prática para o Tratamento de Conteúdo e Interface em Ambientes Informacionais Digitais. Rio de Janeiro: LTC, 2011.

CAMPOS, Rosana; PAIVA, Denise; GOMES, Suely. Gestão da informação pública: um estudo sobre o Portal Transparência Goiás. Revista Sociedade e Estado, v. 28, n. 2, p. 764-781, 2013.

BRASIL. Controladoria Geral da União. Guia de Orientação para a gestão de Ouvidorias. Brasília: 2013. Disponível em: <http://www.cgu.gov.br/assuntos/ouvidoria/produtos-eservicos/consulta-publica/arquivos/produto_5_gestao_de_ouvidorias.pdf $>$. Acesso em: 22 out. 2018.

CINNANTI, Cristina Jacobson Jácomo. Portais do Legislativo: um estudo sobre a usabilidade e a efetividade do portal da Câmara Legislativa do Distrito Federal. 2011. Monografia (Especialização em Gestão Pública Legislativa) - Programa de Pós-Graduação, Centro de Formação, Treinamento e Aperfeiçoamento, Brasília.

CRUZ-RUBIO, César Nicandro. O que é (e o que não é) governo aberto? Uma discussão conceitual. Revista Temas de Administração Pública, v. 10, n. 1, p. 129-148, 2015.

CYBBIS, Walter; BETIOL, Adriana Holtz; FAUST, Richard. ERGONOMIA E USABILIDADE: Conhecimentos, Métodos e Aplicações. 2.ed. São Paulo: Novatec Editora, 2010 .

DIAS, Cláudia. Usabilidade na WEB: Criando portais mais acessíveis. 2. ed. Rio de Janeiro: Alta Books Ltda, 2006.

FAIRBSANS, Jenille; PLOWMAN, Kenneth D.; RAWLINS, Brad L. Transparency in government communication. Journal of Public Affairs, v. 7, n. 10, p. 23-37, 2007.

FERRACIOLI, Paulo; HERMAN, Fellipe. Habilitando o cidadão para a transparência: análise de portais estaduais do executivo e legislativo. In: Encontro Anual da Associação Nacional de PósGraduação e Pesquisa em Ciências Sociais, 42., 2018, Caxambu. Anais [...]. Caxambu: 22 a 26 de outubro de 2018.

FONTANA, Nádia. Assembleia realiza primeira transmissãoco mintérpreteem libras. Disponível em: <http://www.assembleia.pr.leg.br/comunicacao/noticias/assembleia-realiza-primeiratransmissao-com-interprete-em-libras >. Acesso em: 17 nov. 2019.

FRICK, Maria. Translucent States: Political Mediation of E-Transparency. International Journal of Electronic Government Research, v. 4, n. 3, p. 81-102, 2008.

LEMBRE todas as manchetes do escândalo dos Diários Secretos da Assembleia do Paraná. 2010. Gazeta do Povo Online. 15/04/2010. Disponível em: <https://www.gazetadopovo.com.br/vidapublica/especiais/diarios-secretos/lembre-todas-as-manchetes-do-escandalo-dos-diariossecretos-da-assembleia-do-parana-03qjgbghuegc7yo7yqjikelam/>. Acesso em: 29 dez. 2019.

GOMES, Wilson; AMORIM, Paula Karini; ALMADA, Maria Paula. Novos desafios para a ideia de transparência pública. In: Congresso da Associação Brasileira de Pesquisadores em Comunicação e Política, 6., 2015, Rio de Janeiro. Anais [...]. Rio de Janeiro: 22 a 24 de abril de 
2015.

GOMES, Wilson; AMORIM, Paula Karini; ALMADA, Maria Paula. Novos desafios para a ideia de transparência pública. E-Compós, v. 21, n. 2, 2018.

GOMES, Wilson. DEMOCRACIA DIGITAL: QUE DEMOCRACIA? In: Congresso da Associação Brasileira de Pesquisadores em Comunicação Política, 4., Rio de Janeiro. Anais [...]. Rio de Janeiro: 13 a 15 de abril de 2011.

HELD, David. Modelos de Democracia. 1 ed. Tradução: Alexandre Sobreira Martins. Belo Horizonte: Paidéia, 1987.

KNIESS, Andressa Butture. Comunicação pública e transparência governamental em redes sociais digitais: o caso da Controladoria-Geral Da União (CGU). Dissertação (Mestrado em Ciência Política). Centro de Ciências Humanas da Universidade Federal do Paraná, 2019.

KOHLBACH, Karlos; BREMBATTI, Katia; ALBERTI, James; TABATCHEIK, Gabriel. 2.178 atos secretos da Assembleia. Gazeta do Povo Online. 20/03/2010. Disponível em: https://www.gazetadopovo.com.br/vida-publica/especiais/diarios-secretos/2178-atos-secretosda-assembleia-03s8d9ws9m8ptlmr37nkm4dhq/>. Acesso em: 29 dez. 2019.

KOWALSKI, Rodolfo Luis. Um em cada cinco paranaenses possui algum tipo de deficiência. 2019. Bem Paraná Online. 11/04/2019 Disponível em: <https://www.bemparana.com.br/noticia/um-em-cada-cinco-paranaenses-possui-algum-tipo-dedeficiencia\#.XdHPzldKg2w>. Acesso em: 17 nov. 2019.

MARGETTS, Helen. The Internet Transparency. The Political Quarterly, v.82,n. 4, p. 518-521, 2011.

MARQUES, Francisco Paulo Jamil Almeida; PEREIRA, Marcus Abilio. E-Government. In: MAZZOLENI, G.; The International Encyclopedia of Political Communication. Chichester: John Wiley \& Sons, 2015.

MARQUES, Francisco Paulo Jamil Almeida. Ciberpolítica: conceitos e experiências.

Salvador, Edufba, 2016.

MARSH, Kevin. The illusion of transparency. The Political Quarterly, v.82, n. 4, p. 531-535, 2011.

MEIJER, Albert. Understanding modern transparency. International Review of Administrative Sciences, v. 75, n. 2, p. 255-269, 2009.

NASCIMENTO, José Antonio Machado do; AMARAL, Sueli Angélica do. Avaliação de usabilidade na internet. Brasília: Thesaurus, 2010.

NIELSEN, Jakob; LORANGER, Hoa. Usabilidade na web: Projetando Websitescom qualidade. Rio de Janeiro: Elsevier, 2007.

NOVECK, Beth Simone. The Future of Citizen Participation in the Electronic State. In: INTERNATIONAL WORKING CONFERENCE ON THE LANGUAGE-ACTION PERSPECTIVE ON COMMUNICATION MODELLING, 9. Anais [...]. New Brunswick: Rutgers University, The State University of New Jersey, 2 a 3 de junho de 2004.

PARANÁ. Decreto Estadual ${ }^{\circ} \mathbf{1 0 . 2 8 5 / 2 0 1 4}$ de 25 de fevereiro de 2014. Dispõe sobre os procedimentos do Poder Executivo, que garante o acesso à informação, nos termos da legislação vigente. Curitiba, PR, fev. 2014. Disponível em: < https://www.legislacao.pr.gov.br/legislacao/listarAtosAno.do?action=exibir\&codAto=1 14209\& codItemAto=722863\#722863 >. Acesso em: 16 nov. 2019.

PINHEIRO, Paulo Sérgio. Autoritarismo e transição. Revista USP, n. 9, p. 45-56, 1991.

RIBEIRO, Alexandro. Assembleia lança edital de R\$ 30 milhões em publicidade. Plural. Disponível em: <https://www.plural.jor.br/noticias/assembleia-legislativa-quer-gastar-r-30- 
milhoes-em-publicidade/>. Acesso em: 29 dez. 2019.

SILVA, Maria Paula Almada e. Avaliação da e-transparência em portais de Governos nacionais: uma comparação entre Brasil, Estados Unidos e Reino Unido. 2017. Tese (Programa de Pós-Graduação em Comunicação e Cultura Contemporâneas). Faculdade de Comunicação, Universidade Federal da Bahia.

SILVA, Sivaldo Pereira da; SANTOS, Ébida Rosa dos; RABELO, Leon Eugênio Monteiro; LUCIANO, Mariah SampaioF. Avaliando a política de Dados abertos no Legislativo brasileiro: análise qualitativa dos datasets da Câmara dos Deputados. Revista Compolítica,v. 10, n. 1, 2020.

SCHNEIDER, Wilnei Aldir; OLIVEIRA, Tainá Apoema Bueno de; BARNI, Gabriel de Andrade Conradi; FERREIRA, Marcelo Gitirana Gomes; TEZZA, Rafael. Usabilidade e transparência da informação: um estudo do aplicativo Transparência Móvel-SC. Navus - Revista de Gestão e Tecnologia, v. 8, n. 4, 2018.

SOUZA, Vidália Maria Ferreira de. Um estudo sobre acessibilidade e usabilidade com ênfase na terceira idade. 2009. Monografia (Especialização em Informática) - Setor de Ciências Exatas, Universidade Federal do Paraná, Curitiba.

STABILE, Max. Democracia Eletrônica para quem? Quem são, o que querem e como os cidadãos avaliam o portal da Câmara dos Deputados. 2012. Dissertação (Mestrado em Ciência Política) - Instituto de Ciência Política, Universidade de Brasília, Brasília.

VENTURINI, Tommaso; BOUNEGRU, Liliana; GRAY, Jonathan; ROGERS, Richard. A reality check (list) for digital methods. New Media \& Society, v. 20, n. 11, p. 4195-4217, 2018.

Artigo recebido em: 2020-07-31

Artigo reapresentado em: 2020-10-26

Artigo aceito para publicação em: 2020-11-09 